\title{
Frequency of meaning use for ambiguous and unambiguous words
}

\author{
ZENZI M. GRIFFIN \\ University of Illinois at Urbana-Champaign, Urbana, Illinois
}

\begin{abstract}
When using verbal stimuli, researchers usually equate words on frequency of use. However, for some ambiguous words (e.g., ball as a round object or a formal dance), frequency counts fail to distinguish how often a particular meaning is used. This study evaluates the use of ratings to estimate meaning frequency. Analyses show that ratings correlate highly with word frequency counts when orthographic and meaning frequencies should converge, are not unduly influenced by semantic factors, and may provide a better measure of relative meaning dominance than the word association task does. Furthermore, the ratings allow researchers to equate or manipulate frequency of meaning use for ambiguous and unambiguous words. Ratings for 211 words are reported.
\end{abstract}

Lexically ambiguous words are widely used in psycholinguistic research. In word recognition studies, homonyms, ${ }^{1}$ such as (baseball and vampire) bat, have been used to study context and frequency-of-meaning effects in lexical access (for a review, see Simpson, 1984, 1994), number-of-meanings effects (e.g., Millis \& Button, 1989; Rubenstein, Garfield, \& Millikan, 1970), summation of priming (Balota \& Paul, 1996), and other issues. Homophones, such as steel and steal, have been used to explore orthographic priming effects (e.g., Grainger \& Ferrand, 1994 ) and to test the influence of phonology on visual word recognition processes (e.g., Fleming, 1993; Jared \& Seidenberg, 1991; Van Orden, 1987). Homographs with different pronunciations, such as wind, pronounced as /wajnd/ or /wInd/, have also been used to study these questions (e.g., Kawamoto \& Zemblidge, 1992). In word production research, homonyms and homophones have been used to investigate open- versus closed-class vocabulary differences (Dell, 1990), the locus of word frequency effects (Jescheniak \& Levelt, 1994), the effect of phonological priming on word selection (Griffin, 1995), phonology's role in subject-verb agreement errors (Bock \& Eberhard, 1993), and the relationship between lexical processing stages (Cutting \& Ferreira, 1999). However, part of what makes ambiguous words interesting - namely, the association of a single form with multiple meanings-also makes

The norming study was conducted at the University of Illinois at Urbana-Champaign while the author was supported by a National Science Foundation Fellowship. The research was made possible, in part, by grants from the National Institutes of Health (R01-HD21011) and the National Science Foundation (SBR 94-1 1627). Thanks to Kathryn Bock, Victor Ferreira, Leslie Twilley, an anonymous reviewer, and, especially, Gary Dell for suggestions in the preparation of this manuscript and to Urbano Chaidez and Edyta Kania for their hard work and patience in data entry. Correspondence concerning this article should be sent to Z. M. Griffin, Department of Psychology, Stanford University, Jordan Hall, Bldg. 420, Stanford, CA 94305-2130 (e-mail: griffin@) psych.stanford.edu). it difficult to equate them with unambiguous words on the important factor of frequency of meaning use.

Word frequency effects are ubiquitous in word recognition (see, e.g., Forster \& Chambers, 1973) and production (see, e.g., Oldfield \& Wingfield, 1965) tasks. Because of this, care is usually taken to match verbal stimuli and responses on frequency of use. For unambiguous words, estimating and controlling word frequency is fairly straightforward, because measures of phonological- and orthographic-form frequency are highly correlated, and both reflect the frequencies with which meanings are used. In other words, the frequencies of perceiving or producing the form tent, /tent/, and the meaning temporary shelter for campers are probably similar. Thus, an experimenter generally need not be concerned about which type of frequency may have the greatest influence in a task. However, for ambiguous words, orthographic, phonological, and meaning frequencies may vary. To take an extreme case, the form / rajt/ has a phonological-form frequency combining the uses of rite, wright, write, and right. Each orthographic form has its own frequency. For rite, wright, and write, orthographic-form frequency may correspond closely to the frequency with which their meanings are used. In contrast, the orthographic form right has meanings related to direction, correctness, politics, and privileges. If frequency of phonological form (e.g., /rajt/) is influential in a task, an orthographic frequency count (e.g., for right only) underestimates the use of /rajt/. Alternatively, if the frequency of meaning use (e.g., the directional right) is the most important index of use in a task, orthographic frequency (which covers all rights) overestimates use of any one meaning of right. Naturally, all types of frequency may be relevant in a task, in which case a measure of each is important.

Fortunately, there are frequency counts that provide estimates for each orthographic form and grammatical class of a word in speech or text (e.g., the CELEX database; Baayen, Piepenbrock, \& van Rijn, 1993; Francis \& 
Kučera, 1982). Some of these databases provide separate counts for each meaning of homophones (do and dew), homographs of different grammatical classes (/wajnd/ and /WInd/), and homonyms of different grammatical classes (the noun and verb meanings of watch). Combining these separate counts for each spelling and grammatical class offers a way to estimate orthographic or phonological frequency. Meaning frequency is a different matter. With one exception (Lorge, 1949; Lorge \& Thorndike, 1938), frequency counts do not differentiate between the different meanings of homonyms that share grammatical class, such as ball (meaning a round object or a formal dance), and these are perhaps the most commonly used ambiguous words in experiments.

Typically, researchers rely on dominance from word association norms to determine the relative frequency of different meanings for same-class homonyms (i.e., ball is more commonly used for a round object than for a formal dance; see, e.g., Cutting \& Ferreira, 1999; Onifer \& Swinney, 1981). Several sets of word association norms have been published to aid researchers in determining dominance and in manipulating the relative frequencies of homonym meanings (e.g., Cramer, 1970; Gorfein, Viviani, \& Leddo, 1982; Kausler \& Kollasch, 1970; Nelson, McEvoy, Walling, \& Wheeler, 1980; Twilley, Dixon, Taylor, \& Clark, 1994). However, such norms are inadequate for matching a homonym's meaning frequency to that of an unambiguous word, because there is no equivalent measure in word associations for these. Furthermore, the relationship between associative dominance and actual meaning frequency is unclear.

In a study of word associations to unambiguous words, de Groot (1989) found that there were more word association responses to words of high imageability than to words of low imageability and that it took less time to generate an associate to a highly imageable word. The effect of stimulus-word frequency on the speed and number of associations was considerably weaker and, in some experiments, completely absent. This raises the possibility that dominance in word association norms for ambiguous words may be more influenced by the relative imageability of the meanings than by their relative frequency. Consider the homophone can. In Neison et al.'s (1980) association norms, 29 responses were associated to the container meaning, whereas only 8 responses were related to the ability meaning. In contrast, Francis and Kučera (1982) list the modal auxiliary (which is associated with the ability meaning) as having a frequency of 2,192 occurrences per million, whereas the noun (container meaning) has a frequency of 12 . Thus, there may be a nonmonotonic relationship between associative dominance and meaning frequency, particularly when meanings differ in imageability or in the richness of their semantic features (Kausler \& Kollasch, 1970). This raises the possibility that findings of processing differences between dominant and subordinate homonym meanings (cf. Simpson, 1994) may be attributable to imageability, rather than to meaning frequency.
Past studies (e.g., Carroll, 1971; Shapiro, 1969; Tryk, 1968) have shown that subjective frequency ratings for orthographic forms correlate highly with objective frequency measures in general. One goal of the present study was to validate the use of such ratings as estimates of meaning frequency. Another goal was to compare the obtained ratings of meaning frequency with dominance measures from word association norms and frequency counts, in order to validate the use of ratings as measures of relative meaning frequency for ambiguous words. As an integral part of this effort, over 200 words were normed. Participants were asked to rate words according to how often they used the words' meanings in speech. Ratings were collected for homonyms of same and different grammatical classes, for homophones, and for unambiguous words. The inclusion of various types of ambiguous words allowed comparisons to be made between objective and subjective measures that would not otherwise be possible. For example, homophones are ambiguous when presented auditorily, so word associations may be collected for them (G. G. Galbraith \& Taschman, 1969). Because each homophone meaning has a distinct spelling, word frequency counts should correspond to meaning frequencies, allowing comparison between measures of meaning dominance from frequency counts, those from frequency ratings, and those from word associations. The frequency ratings for all words are presented in the Appendix.

\section{METHOD}

\section{Participants}

Twenty-four students at the University of Illinois at UrbanaChampaign participated to fulfill a requirement for an introductory psychology course. They were all native speakers of American English.

\section{Apparatus}

A Macintosh Quadra 800 with a 17 -in. monitor was used to present the stimuli and record the ratings.

\section{Materials}

Although linguistic tests for ambiguity exist, they are unreliable (Geeraerts, 1993). Rather than being strictly ambiguous or unambiguous, words appear to lie on a continuum with a single meaning at one end, multiple unrelated meanings at the other, and clusters of more-or-less related senses in the middle (see, e.g., Tuggy, 1993). Thus, determining the number of distinct meanings that a word possesses relies ultimately on subjective criteria. The author imposed a final classification on each word, using her own intuition after norming was completed. Because some words were only recognized as ambiguous at this point, a few ambiguous words received ratings for only one meaning. The normed items consisted of 119 ambiguous, 73 unambiguous, and 20 questionably unambiguous words. The unambiguous words were chosen to provide potential controls for ambiguous stimuli matched in grammatical class, phonological length, and initial phoneme. The questionable items were not included in comparisons between word types. Some of these words were homophonous with inflected words (e.g., new-knew, pause-paws), and some had secondary meanings only in technical vocabularies (e.g., phone as used in phonology and pan meaning to rotate a camera). A few excluded items had subordinate meanings that seemed unlikely to be in the average vocabulary (e.g., the homonym nap (a downy surface) and the homophone heart (homophonous with hart, a deer). 
Figure 1 illustrates the classification of the words used in this study, along with examples of each. Words that are ambiguous in multiple ways were assigned to the category that best reflected this-in other words, the rightmost appropriate category in Figure 1. For example, plane is homophonous with plain, which makes it a homophone, but it also has meanings that share the same spelling and grammatical class, so it was analyzed as a same-class homonym. Of the ambiguous words, 62 were homophones (i.e., sharing sound but not spelling). Among these were 29 word pairs, 2 words homophonous with words in other ambiguity categories, and 2 words with homophones that were not rated. There were 31 items classified as different grammatical class homonyms ( 11 pairs at the same level of ambiguity, 2 homophonous with words in other groups, 7 alone), and 25 items were considered to be same grammatical class homonyms (12 pairs, 1 alone). A short definition was written for each word, based loosely on its definition in Webster's New World Dictionary of American English (1991).

The classification of words for this study was validated against entries in Webster's Dictionary (1991) by counting the number of entries of the same grammatical class per orthographic form. As was expected, words classified as same-class homonyms had the highest mean number of entries $(M=1.56)^{2}$ per spelling and grammatical class. Words that were unambiguous (1.14) and homophones (1.19) had somewhat fewer entries than did different-class homonyms (1.32). The differences between same-class homonyms and other ambiguity categories were evaluated with one-tailed unpaired $t$ tests. These comparisons indicated that same-class homonyms had significantly more entries than did unambiguous words and homophones $[t(96)=3.92, p<.0001$, and $t(85)=2.81, p<.005$, respectively] and marginally more than did different-class homonyms $[t(54)=1.30, p<.10]$. The $t$ tests support the characterization of the same-class homonyms included in this study as possessing more meanings per form and grammatical class than the other categories did. Because word frequency counts typically follow the organization of dictionaries, except in distinguishing between meanings within the same grammatical class and spelling, frequency counts should be less representative of meaning use for same-class homonyms than for other words. Therefore, insofar as ratings are based on meaning frequency, the correlation between ratings and counts should be lower for same-class homonyms than for other words.

\section{Procedure and Design}

With the use of a variant of standard psychophysical rating tasks (Carroll, 1971; Shapiro, 1969), participants were asked to rate how often they typically said a word, using a particular meaning. They were told to rate meaning use relative to the other items in a list. The instructions were very similar to those of Carroll, except that the participants were asked to estimate frequency of spoken use, rather than written use, and frequency of meaning rather than form. The critical part of the instructions read as follows.

[W]e want to find out how often you say certain words. Suppose that the word "milk" has a value of 100 representing how often you say it. We would like you to give numbers to other words in such a way that the numbers give your own impression of how often you use them in speaking. Thus, if a word seems twenty times as frequent as another, you would give it a number twenty times as large. If, on the other hand, it seems only half as frequent, give it a number only one-half as large. You may use fractions, decimals, or whole numbers, but not negative numbers. Only use zero if you never have used a word. ... Next to each word is a definition. When you decide how often you say a word we want you to think of the meaning of the word that is in the definition.

As in Carroll (1971), the word in the instructions (milk) was only used as an example, and participants were allowed to set their own criteria. Every participant was presented with five practice items, selected to represent a wide frequency range, in random order. Definitions appeared next to all the words, so that the intended meaning would be clear. Two lists of items were constructed in such a way that members of ambiguous word pairs appeared on different lists. As a reliability check, 11 words appeared on both lists with either identical definitions or minor changes in wording. Most of these were unambiguous or excluded questionable words, and one was a homonym (rash). Other than these, words were not repeated with the same definition or intended meaning. Each participant saw both lists, and the order of list presentation was counterbalanced across participants. Between lists, the participants performed a short, unrelated norming task that took about $5 \mathrm{~min}$ to complete. One list contained 113 items, and the other 109. Within each list, word order was a different random sequence for each participant. Approximately 22 items were visible at a time. The participants entered their ratings with a number keypad and used arrow keys to move up and down the lists.

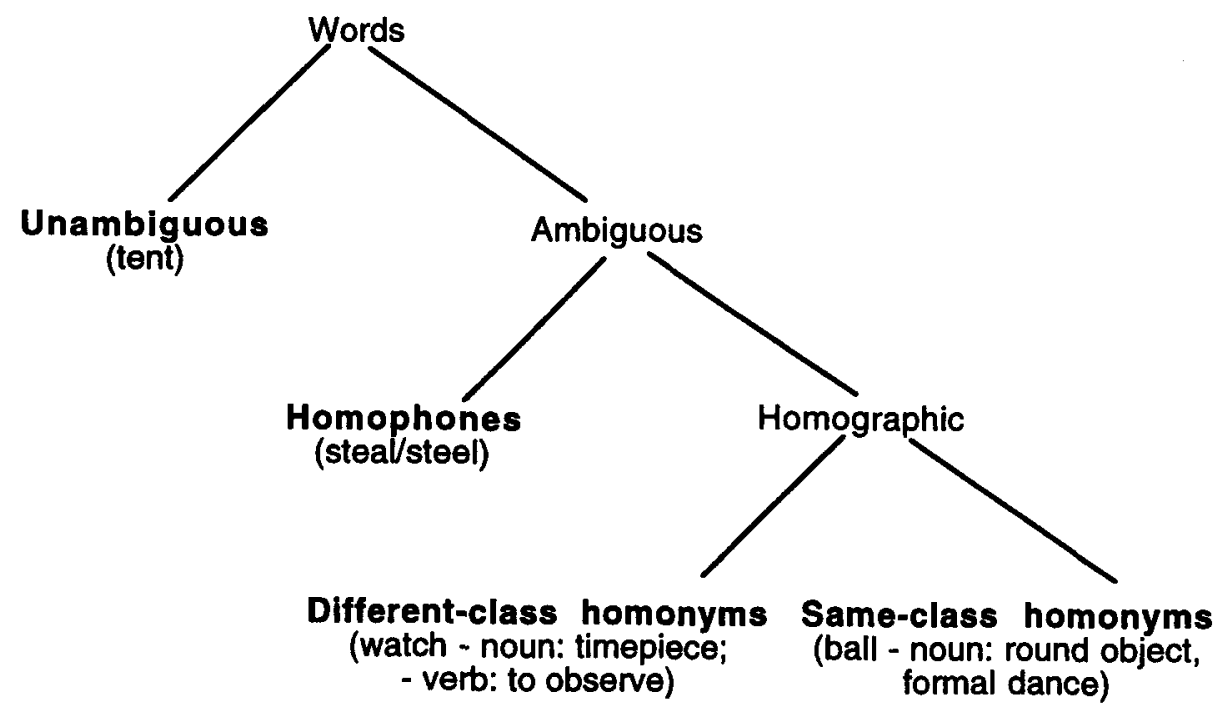

Figure 1. Diagram and examples of word categories used in this study. 


\section{Scoring}

For each word that a participant rated, a $z$ score based on the rating's deviation from the participant's mean rating was calculated. This is similar to the method used by Carroll (1971), except that ratings were also log-transformed in Carroll's study. For each item, a median $z$ score was calculated by taking the median score across participants.

\section{RESULTS AND DISCUSSION}

There was a great deal of variety in the scales used by participants in estimating frequency of meaning use. One participant found $0-30$ to be a sufficiently broad range, whereas another used numbers ranging from $10^{-12}$ to $10^{7}$. The distribution of median $z$ scores for the 222 rated words is shown in the top panel of Figure 2, and for comparison, the distribution of spoken frequency counts from CELEX (Baayen et al., 1993) for the same words is shown in the bottom panel. The mean of the median $z$ scores was -0.090 , with a standard deviation of 0.436 . The homophone $n o$ received the highest median $z$ score
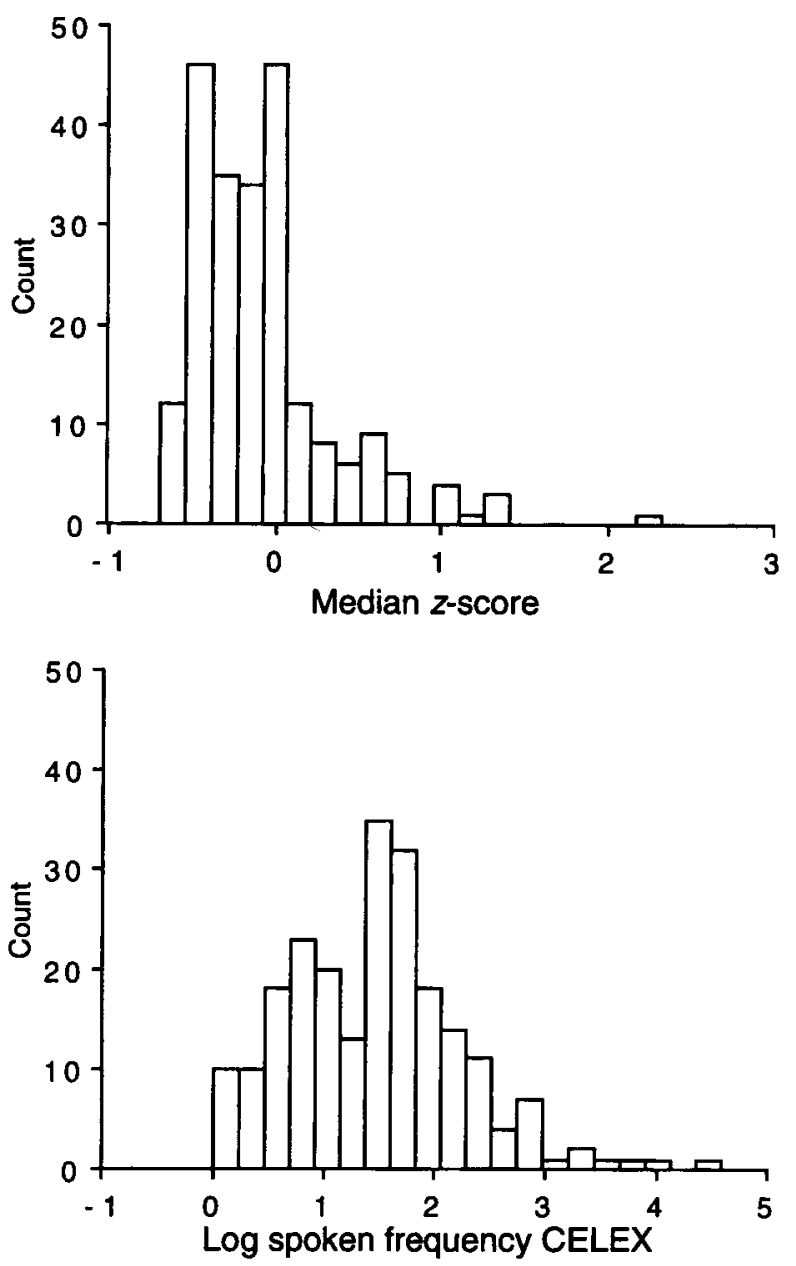

Figure 2. Top panel: distribution of median $\mathrm{z}$ scores for all ratings of meaning frequency. Bottom panel: distribution of log spoken frequency counts from CELEX for the same words.
(2.312), and the unambiguous word reef received the lowest $(-0.690)$.

\section{Rating Meaning Use Versus Form Use}

Two different analyses were employed to determine whether the participants were rating meaning frequency rather than orthographic-form frequency. In the first, the median $z$ scores for the 11 repeated words were compared with the median $z$ scores for the 11 different-class homonym pairs. If the participants did not attend to definitions, there should have been as little variability between the first and the second ratings given to a homonym, such as watch, as there was for the first and the second ratings given to an unambiguous word, such as tent. Note that this is a conservative test, because equivalent rating differences were also predicted if the homonyms had similar meaning frequencies. The absolute differences between median $z$ scores for homonym pairs $(0.209)$ were greater than those for repeated words $(0.108)$. This difference was marginally significant in an unpaired one-tailed $t$ test $[t(20)=1.68, p<.06]$.

In the second analysis, correlations were calculated between median $z$ scores and objective measures of frequency. Objective frequency counts conflate meanings for sameclass homonyms. Thus, if median $z$ scores reflect meaning frequencies, ratings for same-class homonyms should have lower correlations than those for other word types. Alternatively, if the participants ignored the definitions and rated orthographic frequency, median $z$ scores for different-class homonyms (which have their orthographicform frequencies divided among grammatical classes) should show the lowest correlations with frequency counts. Frequency counts for members of other word types are not systematically divided between different grammatical classes.

The objective frequency measures were taken from Francis and Kučera (1982) and the CELEX database (Baayen et al., 1993). Although they are somewhat old, the Francis and Kučera counts (abbreviated F\&K) were included because they are still often used by researchers. Another measure of written frequency was taken from CELEX, which is based on a much larger (more than 16 million words) and more recent database than that of Francis and Kučera. CELEX also provides a measure of spoken frequency, based mostly on British English sources and a relatively small sample ( 1.3 million words). The frequencies corresponding to the grammatical class implied by the words' definitions were used. Correlations were calculated using base-10 logarithms of these counts in occurrences per million plus one. Words with no occurrences in a database thus received a log frequency of zero. The three counts are highly correlated [log written and log spoken CELEX, $r(211)=.94 ; \log$ written CELEX and $\log \mathrm{F} \& \mathrm{~K}, r(211)=.94 ; \log$ spoken CELEX and $\log \mathrm{F} \& \mathrm{~K}$, $r(211)=.89, p \mathrm{~s}<.0001]$, but all three were used, because of their differences in sample sizes and sources. The logtransform of frequency counts is commonly used in studies of reaction time to words (Oldfield \& Wingfield, 1965). 
For calculating correlations with meaning ratings, there was no reason a priori to prefer log-transforms to untransformed counts, but both produced a similar pattern of results, with the log-transformed counts showing slightly stronger correlations with ratings.

Pooling over word types, there was a significant relationship between rated meaning frequency and measures of frequency from various corpora (only the first $z$ score was included for repeated items). Ratings correlated moderately with $\log$ frequencies $[r(211)=.62$ with $\log \mathrm{F} \& \mathrm{~K}$, $r(211)=.66$ with $\log$ written CELEX, and $r(211)=.68$ with $\log$ spoken CELEX, $p$ s $<.0001]$. Table 1 displays the correlations between ratings and these frequency measures, broken down by word type. The Appendix lists the median $z$ scores of individual words alphabetically by word type.

Correlations between ratings of meaning frequency and frequency counts were fairly high and uniformly significant for all word types except homonyms of the same grammatical class. The hypothesis that the participants solely rated frequency of orthographic form predicted that different-class homonyms would have lower correlations with objective counts than would other words. However, only ratings for homophones correlated more highly with counts than ratings for different-class homonyms did, and the difference in correlations for the two word types was not significant. As would be predicted if the participants rated meaning frequency, correlations for same-class homonyms were lower than those for homophones $(z=$ $1.58, p<.06 ; z=2.34, p<.01 ; z=2.19, p<.02$, for $\log$ F\&K, log written CELEX, and log spoken CELEX, respectively). Correlations for same-class homonyms were lower than those for different-class homonyms, although not approaching significance for one word count $(z=.86$, $p<.20 ; z=1.88, p<.04 ; z=1.48, p<.07$, for $\log \mathrm{F} \& \mathrm{~K}$, $\log$ written CELEX, and log spoken CELEX, respectively). However, there was only one marginally significant difference between correlations for same-class homonyms and for unambiguous words $(z=1.33, p<.10$, for $\log$ written CELEX).

Overall, lower correlations between meaning frequency ratings and frequency counts were found for same-class homonyms than for other word types, although the correlations for unambiguous words were lower than expected.

Table 1

Correlations Between Ratings and

Objective Frequency Measures

\begin{tabular}{lccc}
\hline & \multicolumn{3}{c}{ Word Frequency Measure } \\
\cline { 2 - 4 } \multicolumn{1}{c}{ Word Type } & Log F\&K & Log Written & Log Spoken \\
\hline Unambiguous & $.61 \dagger$ & $.63 \dagger$ & $.64 \dagger$ \\
Homophone & $.72 \dagger$ & $.76 \dagger$ & $.78 \dagger$ \\
Homonym, different class & $.64 \dagger$ & $.71 \dagger$ & $.73 \dagger$ \\
Homonym, same class & $.47^{*}$ & .40 & $.47^{*}$ \\
\hline
\end{tabular}

Note-F\&K, Francis and Kučera (1982) frequency counts; written, CELEX occurrences per million in written corpus (Baayen, Piepenbrock, \& van Rijn, 1993); spoken, CELEX occurrences per million in spoken corpus. ${ }^{*} p<.05 .{ }^{\dagger} p<.0005$.
However, it may be the case that ambiguous words have fewer senses per meaning than unambiguous words do, which would make it easier to estimate the meaning frequencies for ambiguous words. The number of subentries in Webster's Dictionary (1991) was calculated for each orthographic form. Consistent with the idea that ambiguous words may have fewer senses per meaning, homophones had a lower mean number of subentries per entry (9.0) than unambiguous words did (10.9). However, by this argument, different-class homonyms should have fewer subentries than do unambiguous words as well, and they did not, even when word class was taken into consideration ( 9.4 vs. 6.0 subentries).

The low correlations between ratings and counts for same-class homonyms were predicted, because frequency counts collapse across all meanings for such words and, therefore, overestimate the use of each meaning. The alternative possibility, that the participants were simply basing ratings on orthographic forms, found no support. That account incorrectly predicted that objective frequency counts for different-class homonyms that were divided by class (e.g., noun and verb watch) would not correlate highly with ratings. Moreover, the larger difference in ratings for different-class homonym pairs, relative to words repeated with the same meaning, further supports the claim that the participants rated frequency of meaning use rather than frequency of form use in this task.

The correlations between ratings and objective counts were smaller than those found by some previous researchers using similar methods. Carroll (1971) and Shapiro (1969) found correlations above 90 between subjective and objective frequency measures. However, there were a number of differences between this study and theirs that could account for the difference in correlations. Both Carroll and Shapiro used a greater range of word frequencies, their analyses were based on log transforms of ratings, and most important, neither were trying to elicit frequency of meaning use. In the present study, objective frequency counts showed correlations in the same range as those found by Tryk (1968) for estimated word use and for Howes's (1954) frequency rankings.

\section{The Influence of Semantic Factors on Ratings}

Earlier studies have found strong effects of semantic factors, such as concreteness, on word association latencies and the number of associates generated (Brown, 1971; Cattell, 1889/1947; Cramer, 1968; de Groot, 1989). These researchers have also noted the ability of such semantic factors to mask or eliminate frequency effects in word associations. Insofar as sensitivity to semantic factors may be common to all subjective measures, they could influence frequency ratings, as well as word associations. Although it is easier to generate associations to concrete words than to abstract ones, past studies of frequency estimation have shown that abstract words are rated higher in frequency than are concrete words (R. C. Galbraith \& Underwood, 1973). The next set of analyses 
evaluates the influence of semantic factors on ratings of meaning frequency.

Correlations between frequency ratings and various measures available from the MRC Psycholinguistic Database (Coltheart, 1981) were calculated. Unfortunately, it was not possible to correlate MRC measures with frequency ratings for homonyms, because the database does not distinguish between different grammatical classes or meanings for the same form. Thus, comparisons were only appropriate for unambiguous words and homophones. As a control for the possible inclusion of words for which frequency and semantic factors were in fact correlated, correlations were also calculated for objective word frequency measures. If abstract word meanings were systematically rated higher in frequency than were concrete meanings, ratings would show greater negative correlations with factors such as concreteness than objective frequencies would. Correlations for each semantic factor with frequency ratings and with $\log \mathrm{F} \& \mathrm{~K}$ are shown in Table 2.

The frequency measures showed similar negative correlations with concreteness and imageability ratings from combined sources (Gilhooly \& Logie, 1980; Pavio, Yuille, \& Madigan, 1968; Toglia \& Battig, 1978). The correlations were stronger for homophones, probably because homophones had greater variability than did unambiguous words in all measures. There were no significant differences between the correlations with each semantic factor for frequency ratings and $\log F \& K($ all $z s<1)$. Ratings of meaning frequency appear no more related to semantic factors than are objective frequency measures. This suggests that frequency ratings were not biased by the concreteness or imageability of words.

\section{Measures of Meaning Dominance}

Next, the frequency ratings, objective frequency counts, and associative dominance were compared as measures of relative meaning frequency for ambiguous words. Currently, the standard method of determining the dominant or high-frequency meaning of a homonym is to select the meaning that receives the greatest proportion of word associations (see, e.g., Hino \& Lupker, 1996; Onifer \& Swinney, 1981). Homonym meanings are considered equibiased or fairly equal in frequency if two meanings produce nearly equal numbers of associations (see, e.g., Rayner \& Duffy, 1986). However, concrete word meanings may be more likely to generate associates than are abstract meanings, diminishing the influence of mean-

\section{Table 2}

Correlations Between Frequency Measures and Semantic Word Information From the MRC Database

\begin{tabular}{cccccccc}
\hline & \multicolumn{3}{c}{ Unambiguous } & & \multicolumn{3}{c}{ Homophone } \\
\cline { 2 - 4 } \cline { 6 - 8 } Measure & Rating & Log F\&K & $N$ & & Rating & Log F\&K & $N$ \\
\hline Concreteness & -.23 & $-.31^{*}$ & 60 & & $-.56 \dagger$ & $-.68 \dagger$ & 52 \\
Imageability & -.15 & -.29 & 62 & & $-.51 \dagger$ & $-.54 \dagger$ & 53 \\
\hline
\end{tabular}

Note-F\&K, Francis and Kučera (1982) frequency counts. ${ }^{*} p<.05$, ${ }^{\dagger} p<.0005$. ing frequency in associative dominance (Brown, 1971; Cramer, 1968; de Groot, 1989). If ratings of meaning frequency truly reflect frequency of meaning use, the ratings may provide an alternative and, perhaps, superior measure of meaning dominance.

Analyses were performed on dominance measures for homophones, such as steal and steel, rather than for homonyms. ${ }^{3}$ Because the separate meanings of homophones are identified by spelling, objective frequency counts were expected to reflect meaning frequencies quite well. A measure of associative dominance came from G. G. Galbraith and Taschman's (1969) collection of word associations to auditorily presented homophones. For the 18 homophone pairs for which there were both frequency ratings and associations, the higher and the lower frequency members were determined on the basis of each measure. Associative dominance had a low level of correspondence with meaning dominance, on the basis of objective frequency measures. Associative dominance agreed with dominance in the written CELEX database for 11 of 18 pairs. For 10 of 18 pairs, associative dominance agreed with dominance in spoken CELEX and F\&K. These patterns did not differ significantly from chance, according to sign tests. Dominance in word associations agreed no better with estimates of meaning dominance based on frequency ratings (10 of 18 ). In contrast, dominance in frequency ratings matched dominance measures based on objective measures more often than would be expected by chance ( 15 of 18 with written CELEX, 14 of 18 with spoken CELEX, and 16 of 18 with $\mathrm{F} \& \mathrm{~K}, p s<.02$ ). So, for the same set of homophones, objective frequency counts and ratings of meaning frequency showed a high level of agreement, whereas associative dominance agreed only at chance levels with meaning dominance, as measured in frequency counts and ratings.

Next, the differences between homophone pairs in a variety of measures were calculated, and correlations between differences were examined. Rather than simply indicating how often measures of dominance agreed with one another, the correlations between differences indicate the degree to which measures agree in magnitude of dominance. Insofar as dominance in word associations is associated with greater frequency of use, differences between the homophone pairs in proportion of associates generated should correlate positively with differences in frequency. Insofar as differences between homophone pairs in word associations are due to concreteness of the meanings or imageability, such differences should correlate positively with word association differences. The same logic holds for ratings of meaning frequency. The upper portion of Table 3 shows the correlations between word association differences and other measures of frequency and semantic factors. For comparison, the correlations for written CELEX frequency in millions and its $\log$ are shown below for the same items. The correlations were calculated for all homophone pairs in G. G. Galbraith and Taschman's (1969) norms. Out of a maximum of 88 , values for both homophone meanings could be ob- 
Table 3

Word Association and Rated Frequency Differences for Homophone Pairs (e.g., week/weak) Correlated With Differences Along Other Dimensions

\begin{tabular}{lcccccccc}
\hline Variable 1 & Written & LogWritten & Spoken & LogSpoken & F\&K & LogF\&K & Conc & Image \\
\hline Word association differences & .03 & $.55 \ddagger$ & -.02 & $.47 \ddagger$ & .00 & $.48 \ddagger$ & $.23^{*}$ & $.32 \dagger$ \\
Written CELEX & & $.44 \ddagger$ & $.96 \ddagger$ & $.48 \ddagger$ & $.96 \ddagger$ & $.43 \ddagger$ & -.20 & -.20 \\
LogWritten CELEX & & & $.31 \dagger$ & $.92 \ddagger$ & $.49 \ddagger$ & $.93 \ddagger$ & $-.28^{*}$ & -.13 \\
Ratings of meaning frequencies & $.49 \dagger$ & $.56 \dagger$ & $.54 \dagger$ & $.48^{*}$ & $.50 \dagger$ & $.60 \ddagger$ & $-.62 \dagger$ & $-.50^{*}$ \\
Written frequencies & & $.58 \dagger$ & $.99 \ddagger$ & $.45^{*}$ & $1.00 \ddagger$ & $.52 \ddagger$ & $-.50^{*}-.55 \dagger$ \\
LogWritten frequencies & & & $.62 \ddagger$ & $.94 \ddagger$ & $.57 \dagger$ & $.94 \ddagger$ & $-.71 \ddagger-.60 \dagger$ \\
\hline
\end{tabular}

Note-Written, CELEX occurrences per million in written corpus; spoken, CELEX occurrences per million in spoken corpus; F\&K, Francis and Kučera written frequency; conc, concreteness ratings; image, imageability ratings. For correlations with word association differences, $N=78-87$; for correlations with rating differences, $N=24-32 . \quad{ }^{*} p<.05 . \quad{ }^{\dagger} p<.005 . \quad \ddagger p<.0005$.

tained for 78-87 of the pairs. The lower portion of Table 3 shows correlations for differences in ratings of meaning frequency, written frequency, and its $\log$. These were based on all homophonic pairs in the present norms, with 24 to 32 observations contributing to each correlation.

Both word association differences and rated frequency differences correlated significantly and positively with differences in $\log$ frequency, whereas only rated frequency differences correlated significantly with raw frequency differences. This difference in behavior appears primarily to be due to differences between function and content words that were often extreme in raw numbers but average when based on differences in $\log$ frequency. For example, more word associations were made to eye than to $I$, although $I$ occurs 9,617 times more often per million words in the written CELEX database. No other word pair comes close to having such a large raw frequency difference, but the pair's difference in log written CELEX frequency is 1.26-for example, gate/gait and symbol/ cymbal. Because response latencies typically reflect log frequency (Oldfield $\&$ Wingfield, 1965), this may be the more relevant measure of frequency. If so, word associations and frequency ratings would be equivalent in estimating differences in relative meaning frequency.

Both word association and frequency rating differences correlated significantly, albeit differently, with differences in concreteness and imageability ratings. Greater differences in concreteness and imageability correlated positively with differences in word association responses and negatively with differences in rated meaning frequency. For semantic factors, differences in frequency ratings patterned with differences in frequency counts, ${ }^{4}$ with no significant difference between their correlations with concreteness and imageability $(z s<0.6$, for comparisons with raw written frequency). In contrast, correlations with concreteness and imageability for word association differences differed significantly from correlations for frequency counts $(z=2.67, p<.004$, for concreteness and raw written frequency; $z=3.28, p<.0007$, for imageability and raw written frequency; $z=2.84, p<.003$, for imageability and log written frequency). This further suggests that ratings of meaning frequency reflect frequency of use and are less biased by semantic factors than word associations are.

\section{Summary and Conclusions}

The first series of analyses converged on the conclusion that participants rated meaning frequency rather than form frequency. For words that possess approximately one meaning per form, ratings of meaning frequency correlated highly with objective frequency measures, as one would expect. The second set of analyses found that semantic factors had no greater correlations with ratings of meaning frequency than they did with objective frequency counts, although these same semantic factors often affect word associations (Brown, 1971; Cattell, 1889/1947; Cramer, 1968; de Groot, 1989). The final set of analyses compared ratings of meaning frequency and associative dominance as measures of meaning dominance for ambiguous words (i.e., which meaning of ball or week/weak is more common). For an identical group of homophones, frequency ratings agreed with dominance in objective frequency counts, whereas associative dominance did not. Also, differences in rated frequency for pairs of homophones correlated significantly with differences in raw and log frequency, showing correlation patterns with differences in semantic ratings similar to those for differences in objective frequency measures. In contrast, differences between proportion of related word associations showed positive correlations with differences in concreteness and imageability ratings, whereas differences in objective frequency measures did not.

In the past, proponents of subjective measures of word frequency or familiarity have argued that they may actually be more accurate than objective counts when considering infrequent words that are unlikely to appear in small samples (e.g., Carroll, 1971; Gernsbacher, 1984; Tryk, 1968). Now that frequency counts based on far larger corpora exist, there is less of a concern about sampling error for written word frequency counts. However, word frequency counts for spoken English are still based on relatively small samples (e.g., a quarter million in Howes, $1966 ; 1.3$ million in CELEX) and are often from dialects spoken outside North America (as is the case for CELEX). For the words included in this study, spoken and written frequency counts were highly correlated, but this need not always be true. In any case, all of the currently available objective frequency counts fail to differentiate between homonyms belonging to the same grammatical class, 
such as ball, meaning a round object or a formal dance. The exception is Lorge's (1949; Lorge \& Thorndike, 1938) semantic count, which is not widely available, in addition to having a number of discrepancies. So, it often remains necessary to resort to subjective measures for estimating word frequency in speech and for determining the relative meaning frequencies of same-class homonyms.

I presented evidence that collecting ratings of meaning frequency allows researchers to overcome several of the problems associated with other frequency measures. Currently, when researchers attempt to equate ambiguous and unambiguous words on frequency, they use the frequencies of the orthographic forms (Rayner \& Duffy, 1986) or familiarity ratings for forms (e.g., Hino \& Lupker, 1996). As is demonstrated here, it is possible to tap frequency of meaning use rather than form use, thus overcoming a limitation of most objective frequency counts and allowing ambiguous and unambiguous words to be matched on meaning frequency. It should also be possible to collect ratings of sense frequency, thus providing a measure of relatively how often senses of polysemous words are used (e.g., paper as a single document, a substance, a periodical publication, etc.). In general, ratings of meaning frequency provide a way to more accurately estimate and manipulate meaning frequencies of ambiguous words, while allowing them to be equated with unambiguous words on frequency of meaning, orthographic form, phonological form, or all three.

\section{REFERENCES}

Baayen, R. H., Piepenbrock, R., \& van Rijn, H. (1993). The CELEX lexical database [CD-ROM]. Philadelphia: Linguistics Data Consortium, University of Pennsylvania.

Balota, D. A., \& PAUL, S. (1996). Summation of activation: Evidence from multiple primes that converge and diverge within semantic memory. Journal of Experimental Psychology: Learning, Memory, \& Cognition, 22, 827-845.

Bock, K., \& EBERHARD, K. M. (1993). Meaning, sound and syntax in English number agreement. Language \& Cognitive Processes, 8, 57-99.

BRoWN, W. P. (1971). A retrospective study of stimulus variables in word association. Journal of Verbal Learning \& Verbal Behavior, 10 , 355-366.

CARRolL, J. B. (1971). Measurement properties of subjective magnitude estimates of word frequency. Journal of Verbal Learning \& Verbal Behavior, 10, 722-729.

CATTELL, J. M. (1947). Mental association investigated by experiment. In A. T. Poffenberger (Ed.), James McKeen Cattell, 1860-1944: Man of Science (pp. 110-124). Lancaster, PA: Science Press. (Original work published 1889)

Coltheart, M. (1981). The MRC psycholinguistic database. Quarterly Journal of Experimental Psychologv, 33A, 497-505.

Cramer, P. (1968). Word association. New York: Academic Press.

Cramer, P. (1970). A study of homographs. In L. Postman \& G. Keppel (Eds.), Norms of word association (pp. 361-382). New York: Academic Press.

Cutting, J. C., \& Ferreira, V. S. (1999). Semantic and phonological information flow in the production lexicon. Journal of Experimental Psychology: Learning, Memory, \& Cognition, 25, 318-344.

DE GROOT, A. M. B. (1989). Representational aspects of word imageability and word frequency as assessed through word association. Journal of Experimental Psychology: Learning, Memory, \& Cognition, 15 , 824-845.
DELL, G. S. (1990). Effects of frequency and vocabulary type on phonological speech errors. Language \& Cognitive Processes, 5, 313-349.

Fleming, K. K. (1993). Phonologically mediated priming in spoken and printed word recognition. Journal of Experimental Psychology: Learning, Memory, \& Cognition, 19, 272-284.

Forster, K. I., \& ChAMBERS, S. M. (1973). Lexical access and naming time. Journal of Verbal Learning \& Verbal Behavior, 12, 627-635.

Francis, W. N., \& KuČERA, H. (1982). Frequency analyses of English usage: Lexicon and grammar. Boston: Houghton Mifflin.

Galbraith, G. G., \& Taschman, C. S. (1969). Homophone units: A normative and methodological investigation of the strength of component elements. Journal of Verbal Learning \& Verbal Behavior, 8 , 737-744.

Galbraith, R. C., \& Underwood, B. J. (1973). Perceived frequency of concrete and abstract words. Memory \& Cognition, 1, 56-60.

GeERAERTS, D. (1993). Vagueness's puzzles, polysemy's vagaries. $C o g$ nitive Linguistics, 4, 223-272.

GERNSBACHER, M. A. (1984). Resolving 20 years of inconsistent interactions between lexical familiarity and orthography, concreteness, and polysemy. Journal of Experimental Psychology: General, 113, 256-281.

GILHOOLY, K. J., \& LOGIE, R. H. (1980). Age-of-acquisition, imagery, concreteness, familiarity, and ambiguity measures for 1,944 words. Behavior Research Methods \& Instrumentation, 12, 395-427.

Gorfein, D. S., Viviani, J. M., \& LedDo, J. (1982). Norms as a tool for the study of homography. Memory \& Cognition, 10, 503-509.

Grainger, J., \& Ferrand, L. (1994). Phonology and orthography in visual word recognition: Effects of masked homophone primes. Journal of Memory \& Language, 33, 218-233.

GrifFIN, Z. (1995, May). The locus of the word frequency effect in language production. Paper presented at the 67th Annual Meeting of the Midwestern Psychological Association, Chicago.

HiNo, Y., \& LuPKER, S. J. (1996). Effects of polysemy in lexical decision and naming: An alternative to lexical access accounts. Journal of Experimental Psychology: Human Perception \& Performance, 22, $1331-1356$

HowEs, D. (1954). On the interpretation of word frequency as a variable affecting speed of recognition. Journal of Experimental Psychology, 48, 106-112.

Howes, D. (1966). A word count of spoken English. Journal of Verbal Learning \& Verbal Behavior, 5, 572-604.

JARED, D., \& SEIDENBERG, M. S. (1991). Does word identification proceed from spelling to sound to meaning? Journal of Experimental Psychology: General, 120, 358-394.

JeSCHENIAK, J. D., \& LEVELT, W. J. M. (1994). Word frequency effects in speech production: Retrieval of syntactic information and of phonological form. Journal of Experimental Psychology: Learning, Memory, \& Cognition, 20, 824-843.

KaUSLER, D. H., \& Kollasch, S. F. (1970). Word associations to homographs. Journal of Verbal Learning \& Verbal Behavior, 9, 444-449.

KaWA moto, A. H., \& Zemblidge, J. H. (1992). Pronunciation of homographs. Journal of Memory \& Language, 31, 349-374.

LORGE, I. (1949). The semantic count of the 570 commonest English words. New York: Columbia University, Teachers College.

LORGE, I., \& THORNDIKE, E. L. (1938). A semantic count of English words. New York: Columbia University, Teachers College.

Millis, M. L., \& ButTon, S. B. (1989). The effect of polysemy on lexical decision time: Now you see it, now you don't. Memory \& Cognition, 17, 141-147.

Nelson, D. L., McEvoy, C. L., WAlling, J. R., \& WheEler, J. W., JR. (1980). The University of South Florida homograph norms. Behavior Research Methods \& Instrumentation, 12, 16-37.

OLDFIELD, R. C., \& WINGFIELD, A. (1965). Response latencies in naming objects. Quarterly Journal of Experimental Psychology, 17, 273-281.

ONIFER, W., \& SWINNEY, D. A. (1981). Accessing lexical ambiguities during sentence comprehension: Effects of frequency of meaning and contextual bias. Memory \& Cognition, 9, 225-236.

Pavio, A., Yuille, J. C., \& Madigan, S. A. (1968). Concreteness, imagery, and meaningfulness values for 925 words. Journal of Experimental Psychology Monograph Supplement, 76, (3, Pt. 2).

RAYNER, K., \& DUFFY, S. A. (1986). Lexical complexity and fixation 
times in reading: Effects of word frequency, verb complexity, and lexical ambiguity. Memory \& Cognition, 14, 191-201.

RosenZwerg, M. R., \& MCNEILL, D. (1962). Inaccuracies in the semantic count of Lorge and Thorndike. American Journal of Psychology, 75, 316-319.

Rubenstein, H., Garfield, L., \& Millikan, J. A. (1970). Homographic entries in the internal lexicon. Journal of Verbal Learning \& Verbal Behavior, 9, 487-492.

SHAPIRo, B. J. (1969). The subjective estimation of relative word frequency. Journal of Verbal Learning \& Verbal Behavior, 8, 248-251.

SimPSON, G. B. (1984). Lexical ambiguity and its role in models of word recognition. Psychological Bulletin, 96, 316-340.

SimPSON, G. B. (1994). Context and the processing of ambiguous words. In M. A. Gernsbacher (Ed.), Handbook of psycholinguistics (pp. 359. 374). New York: Academic Press.

Toglia, M. P., \& BATtig, W. R. (1978). Handbook of semantic word norms. New York: Erlbaum.

TRYK, H. E. (1968). Subjective scaling of word frequency. American Journal of Psychology, 81, 170-177.

TugGY, D. (1993). Ambiguity, polysemy, and vagueness. Cognitive Linguistics, 4, 273-290.

TWILley, L. C., Dixon, P., TAYloR, D., \& Clark, K. (1994). University of Alberta norms of relative meaning frequency for 566 homographs. Memory \& Cognition, 22, 111-126.

VAN ORDEN, G. C. (1987). A ROWS is a ROSE: Spelling, sound, and reading. Memory \& Cognition, 15, 181-198.

Webster's New World Dictionary of American English (3rd ed.). (1991). New York: Prentice-Hall.

\section{NOTES}

1. Henceforth, words identical in spelling and sound will be called homonyms, those sharing spelling but not sound will be called homographs, and those sharing sound but not spelling will be homophones. The word ambiguous will be used to cover all of these words and to differentiate them from orthographic and phonological forms that only have related meanings.

2. Often, meanings that I found sufficiently unrelated to make them homonyms fell under one entry in the dictionary (e.g., note as in a message or as used in music, chest as a body part or as a box).

3. Ideally, same- and different-class homonym pairs could be compared in a similar fashion. Unfortunately, among the stimuli, there were only nine different-class pairs that association norms and frequency ratings had in common. Slightly more same-class pairs were shared, but those lacked objective counts for comparison. An attempt was made to use sense frequency counts from Lorge and Thorndike (Lorge, 1949; Lorge \& Thorndike, 1938), but the low level of agreement within these counts, as reported by Rosenzweig and McNeill (1962), as well as between Lorge counts and CELEX counts for different-class pairs, made this an unattractive source.

4. Note that, in the present analyses, ratings never correlated significantly higher with concreteness or imageability than objective frequency measures did. This supports R. C. Galbraith and Underwood's (1973) idea that number of contexts rather than concreteness may have affected their frequency ratings. Use in a greater number of contexts has also been hypothesized as a reason why high-frequency words are produced more quickly and accurately than low-frequency words (Dell, 1990).

APPENDIX

\begin{tabular}{|c|c|c|c|c|c|}
\hline Target & Definition & Median $z$ Score & Target & Definition & Median $z$ Score \\
\hline & Unambiguous Words & & mask & disguise for the face & -0.38 \\
\hline age & length of existence & -0.07 & moon & a satellite revolving around earth & -0.07 \\
\hline $\mathrm{ax}$ & instrument to chop wood & -0.54 & name & title & 1.19 \\
\hline bake & to cook in an oven & -0.27 & nose & something you breathe through & -0.10 \\
\hline beak & a bird's mouth & -0.51 & paint & liquid color & -0.23 \\
\hline beer & an alcoholic drink & 0.62 & patch & a cover for a hole & -0.56 \\
\hline boat & a vessel for traveling on water & -0.41 & pose & to assume a position & -0.37 \\
\hline boat & water vessel & -0.37 & price & cost & 0.18 \\
\hline brag & to boast & -0.30 & price & cost & 0.41 \\
\hline burn & to injure with heat & -0.09 & prize & free gift & -0.21 \\
\hline candle & source of light & -0.46 & pulse & the beating blood in arteries & -0.45 \\
\hline captain & commander of a vessel & -0.51 & reach & to attain; to extend toward a goal & -0.08 \\
\hline chalk & a powdery stick used for drawing & -0.45 & reef & a formation in the ocean & -0.69 \\
\hline choose & to select & -0.11 & ride & a trip & -0.07 \\
\hline cut & an incision, a wound & -0.19 & sand & small rock particles & -0.42 \\
\hline dark & dim, lacking light & 0.48 & say & to utter aloud, speak & 1.01 \\
\hline deep & opposite of shallow & -0.24 & scar & mark of a wound & -0.33 \\
\hline deep & opposite of shallow & -0.34 & scoop & a kind of spoon & -0.46 \\
\hline dent & a hollow in a surface & -0.41 & seat & a place to sit & 0.09 \\
\hline dent & a hollow, an indentation & -0.28 & shark & an animal that lives in the ocean & -0.47 \\
\hline dime & ten pennies & -0.07 & show & a television program & 0.37 \\
\hline dime & ten pennies & -0.12 & sick & ill & -0.04 \\
\hline floor & a level in a building & 0.03 & size & a measure of the space something & -0.07 \\
\hline frost & frozen moisture outside & -0.46 & & occupies & \\
\hline germs & bacteria, carriers of disease & -0.43 & sky & the upper atmosphere, the heavens & -0.01 \\
\hline gulp & swallow & -0.50 & soft & opposite of hard & 0.04 \\
\hline hand & part of the arm below the wrist & 0.53 & soil & dirt & -0.39 \\
\hline hint & a clue & -0.38 & song & a tune & 0.65 \\
\hline hook & curved metal pin that holds things & -0.43 & sour & a sharp, acid taste & -0.23 \\
\hline hunt & search; kill or catch for sport & -0.46 & space & area between things; room & -0.08 \\
\hline job & employment & -0.01 & spy & an undercover information gatherer & -0.51 \\
\hline land & real estate, property, ground & -0.20 & stain & a permanent mark & -0.20 \\
\hline
\end{tabular}


APPENDIX (Continued)

\begin{tabular}{|c|c|c|c|c|c|}
\hline Target & Definition & Median $z$ Score & Target & Definition & Aedian $z$ Score \\
\hline stem & the main stalk of a plant & -0.53 & poll & a survey & -0.52 \\
\hline string & a thin cord & -0.31 & sale* & reduce price & -0.08 \\
\hline tent & a temporary shelter & -0.54 & sight & vision & -0.21 \\
\hline tent & a temporary shelter & -0.56 & site & a location & -0.46 \\
\hline thick & opposite of thin & -0.31 & son & male child & -0.20 \\
\hline thin & opposite of fat & -0.08 & sun & the star that the Earth revolves around & d $\quad 0.01$ \\
\hline thorn & a sharp, pointed growth & -0.44 & steal & to take without permission & -0.17 \\
\hline thumb & part of the hand & -0.27 & steel & a metal & -0.43 \\
\hline tube & a slender pipe & -0.51 & tea & a hot beverage & -0.26 \\
\hline war & armed conflict & -0.19 & tee & golfball holder & -0.51 \\
\hline warm & a degree of heat & 0.64 & waist & between ribs and hips & -0.20 \\
\hline wet & moist & 0.21 & waste & unnecessary use & -0.18 \\
\hline wife & female spouse & -0.17 & wait & to remain, to be ready & 0.30 \\
\hline wing & what birds and planes use to fly & -0.41 & weight & degree of heaviness & 0.15 \\
\hline wise & knowledgeable, full of information & -0.22 & way & direction & 0.25 \\
\hline wise & knowledgeable, full of information & -0.46 & weigh & to measure heaviness & -0.07 \\
\hline wish & to desire, express a want & 0.18 & weak & lack of strength & -0.07 \\
\hline wolf & a wild, dog-like animal & -0.51 & week & seven days & 0.78 \\
\hline & Homophones & & write $\dagger$ & to inscribe; record in words & 1.10 \\
\hline $\mathrm{ad}$ & a commercial & -0.19 & & Different-Class Homonyms & \\
\hline add & to sum, put together & -0.06 & ace $^{*}$ & usually the highest card in a deck & -0.25 \\
\hline be & to exist; to possess some quality & 1.40 & bail* & a deposit to get out of jail & -0.54 \\
\hline bee & an insect & -0.29 & boil* & to heat water until bubbling & -0.39 \\
\hline brake & to slow down & -0.12 & change & to alter & 0.67 \\
\hline break & to shatter, come apart & -0.07 & change & coins & 0.36 \\
\hline cellar & basement & -0.53 & check & a substitute for cash & -0.01 \\
\hline seller & someone who sells things & -0.47 & check & to test, as in to double-check & -0.04 \\
\hline cent & one penny & -0.08 & fair ${ }^{\dagger}$ & unbiased, even, just & -0.06 \\
\hline scent & an odor; smell & -0.22 & fall* & to descend quickly, to drop & -0.07 \\
\hline chute & a funnel & -0.53 & light & a source of illumination & 0.65 \\
\hline shoot & to fire a gun & -0.31 & light & opposite of heavy; lacking mass & 0.08 \\
\hline dam & a blockage of water & -0.55 & park & a recreational area & -0.08 \\
\hline damn & a swear word & 0.16 & park & to position a car & -0.07 \\
\hline dew & moisture formed on surfaces at night & -0.48 & rash* & skin irritation & -0.50 \\
\hline do & to act, perform & 1.39 & rash* & skin irritation & -0.52 \\
\hline die & to cease living & 0.07 & right $\uparrow$ & opposite of left & 0.66 \\
\hline dye & substance for coloring fabric & -0.54 & ring & jewelry worn on a finger & -0.23 \\
\hline fare $\dagger$ & bus ride fee & -0.50 & ring & the sound a telephone makes & 0.07 \\
\hline flour & ground grain used in baking & -0.42 & safe & secure, not in danger & -0.09 \\
\hline flower & a blossom & -0.16 & safe & a container for valuables & -0.37 \\
\hline genes & carriers of hereditary information & -0.26 & shot* & what a gun fires & -0.27 \\
\hline jeans & denim pants & 0.64 & sign & to handwrite one's name & -0.05 \\
\hline hair & threadlike growths on people's heads & 0.46 & sign & a notice, a display of information & -0.05 \\
\hline hare & animal like a rabbit & -0.55 & sink & to descend, move downwards & -0.37 \\
\hline heal & to cure, repair & -0.22 & sink & a water basin & -0.20 \\
\hline heel & back part of the foot & -0.45 & sock* & something worn under shoes & 0.02 \\
\hline hear & to perceive through the ear & 0.67 & stick & a small branch & -0.25 \\
\hline here & in this place; location & 0.99 & stick & to adhere; to fasten something & -0.39 \\
\hline knead & to handle dough & -0.58 & toast & browned bread & -0.22 \\
\hline need & to require & 0.65 & toast & to drink to someone's health & -0.43 \\
\hline know & to possess information about & 1.31 & watch & a timepiece, a small clock & 0.20 \\
\hline no & refusal; negative vote & 2.31 & watch & to look at for a while & -0.07 \\
\hline mail & letters delivered by post office & 0.74 & \multirow{2}{*}{\multicolumn{3}{|c|}{ Same-Class Homonyms }} \\
\hline male & counterpart to female & 0.04 & & & \\
\hline new* & opposite of old & 0.32 & ball & round object used in games & -0.06 \\
\hline none & complete absence & -0.07 & ball & a formal dance & -0.69 \\
\hline nun & a religious woman & -0.55 & bat & a flying creature & -0.58 \\
\hline pain & extreme discomfort, agony & 0.11 & bat & something used to hit a baseball & -0.22 \\
\hline pane & a sheet of glass in a window & -0.51 & bill & a draft of a proposed law & -0.39 \\
\hline peace & calm; freedom from war & -0.09 & bill & a charge for services & -0.07 \\
\hline piece & a part of something & -0.06 & capital & uppercase letter & -0.34 \\
\hline pole & a long rod & -0.43 & capital & seat of government & -0.43 \\
\hline
\end{tabular}


APPENDIX (Continued)

\begin{tabular}{|c|c|c|c|c|c|}
\hline Target & Definition & Median $z$ Score & Target & Definition & Median $z$ Score \\
\hline chest & a large wooden box-like container & -0.55 & build & to construct & -0.25 \\
\hline chest & a body part & 0.03 & close & to shut & 0.76 \\
\hline \multirow[t]{2}{*}{ club } & object used to hit things, such as & -0.33 & head & part of the body above the neck & -0.07 \\
\hline & golfballs & & heart & a bodily organ or the shape of & -0.05 \\
\hline club & an organization & -0.12 & & this organ & \\
\hline date & a day of the year & 0.49 & $\operatorname{man}$ & male human & 0.11 \\
\hline date & a romantic encounter; appointment & 0.26 & $\operatorname{man}$ & male human & 0.44 \\
\hline feet & a measure of length or height & -0.04 & meal & breakfast, lunch, or dinner & 0.24 \\
\hline feet & part of the body below ankles & -0.10 & mouth & oral cavity & 0.02 \\
\hline letter & part of the alphabet & -0.08 & nap & a short period of sleep & 0.09 \\
\hline letter & a written message & 0.00 & neck & part of the body & -0.34 \\
\hline note & a certain tone or pitch in music & -0.24 & pan & cooking utensil & -0.31 \\
\hline note & a short written communication & -0.09 & pause & a time period during which & -0.44 \\
\hline plain* & unadorned, not decorated or special & -0.20 & & nothing happens & \\
\hline plane* & flying vehicle & -0.24 & phone & communication device & 1.06 \\
\hline run* & to move rapidly & 0.65 & red & a bright color & 0.03 \\
\hline tie & clothing worn around the neck & -0.40 & rent & housing payment & -0.23 \\
\hline tie & a draw; a nondecisive outcome & -0.25 & rent & payment for housing & -0.26 \\
\hline & Excluded Questionable Words & & shoe & clothing worn on feet & 0.25 \\
\hline bald & without hair & -0.38 & skate & to move on rollerblades & -0.37 \\
\hline bald & hairless & $\begin{aligned} 0.00 \\
-038\end{aligned}$ & & skin darkened by the sun & -0.16 \\
\hline bell & something that makes noise & -0.25 & world & the planet Earth & -0.07 \\
\hline
\end{tabular}

Note-Homophones are presented in pairs in alphabetical order. *Indicates that the other meaning was not rated. †Indicates that the other meaning falls into a different category, either homophones or different-class homonyms.

(Manuscript received November 22, 1995;

revision accepted for publication May 7,1998 .) 